\title{
FEM simulation research of natural frequency vibration of crankshaft from internal combustion engine
}

\author{
Pawet Magryta ${ }^{1, *}$, Konrad Pietrykowski ${ }^{1}$ and Krzysztof Skiba $^{1}$ \\ ${ }^{1}$ Faculty of Mechanical Engineering, Department of Thermodynamics, Fluid Mechanics and Aviation Propulsion Systems, Lublin \\ University of Technology, ul. Nadbystrzycka 36, 20-618 Lublin, Poland
}

\begin{abstract}
The article presents vibration simulation studies of a crankshaft used in internal combustion engine. The simulation was performed using FEM method. The study was conducted in Abaqus software, and a shaft model was implemented in Catia v5. The influence of a mesh element size on the results of obtained calculations was analysed. A shaft which will be used in the ultralight aircraft engine was the subject of research. Results show the first 10 frequency modes and 12 grid examples for various element sizes, from 9 to $1.3 \mathrm{~mm}$. Moreover, the effect of mesh size on the obtained results is presented. It has been proven that the maximum error for two extreme results (the densest and sparsest grid) is approximately $1.4 \%$; therefore, it is justified to carry out calculations of own vibration on a fatal grid. Results presented herein will be used in the future work on the crankshaft geometry modifications.
\end{abstract}

\section{Introduction}

Internal combustion engines use a crank-piston system to convert reciprocating motion to rotary motion. The crankshaft is a key element of this system. Its torque is not constant over time but varies in complexity, depending on the position of the crankshaft for each cylinder [1]. In many cases the vibration phenomena can be decisive for the proper functioning of the shaft. Vibration can cause an engine as well as an aircraft's work disturbance. The resonance amplification of the vibration amplitude threatens to damage of the shaft and its associated components. Regardless of the dynamic system in which the engine works, the greatest danger to its crankshaft are torsional vibrations. Among of many forces acting in the crank-piston system, crankshaft rotational force is caused by tangential force around the crank. Force which is one of two component forces acting along the connecting rod axis is the periodic force [2]. Its period for a two-stroke engine is $2 \pi$, and for fourstroke engines $4 \pi$ [3]. Variation of force induces acceleration in the crankshaft rotation of the engine, causing the formation of torsional vibrations, which additionally change with the change in shaft speed. The resonance may occur when the frequency of the forced oscillation equals or is multiple of the vibration frequency of the shaft. The vibration frequency of the shaft depends on the size and distribution of the masses, how the shaft is supported and its geometrical properties [4].

Very often design support processes are used in the form of computer simulation. Modern design methods allow for a considerable reduction in design time [5]. In the field of mechanics and machine construction, the use of computing power allows for faster verification of proposed technical solutions [6]. This approach avoids undesirable design errors as well as shortens design time [7, 8]. With the development of computer systems, increased computing power is available. This allows for more complex simulation processes. In the field of mechanics, simulations are mainly used for testing the strength of the tested parts of machines or devices. Most of simulations are based on the so-called FEM $\neg$ Finite Elements Method. The main aspect influencing the accuracy of calculations using this method is a size of the primary computing element. The choice of its shape and size obviously affects the time of calculation but also the accuracy of results $[8,9]$.

This article describes the impact of computational grid selection on results obtained during the simulation of the crankshaft of a diesel engine. Presented methodology will be useful for making new calculations for new crankshafts. The paper presents differences of results, that can be used for study of next engine parts $[10,11,12]$. This engine is a research engine with opposed pistons. It is a propulsion unit that will be used in ultralight aviation. Abaqus FEM software was used to calculate the crankshaft frequency. This program allows to specify a user-defined number of forms of the vibration frequencies of any model. Crankshaft geometry was imported into the environment as a .stp file (Figure 1).

\footnotetext{
Corresponding author: p.magryta@pollub.pl
} 


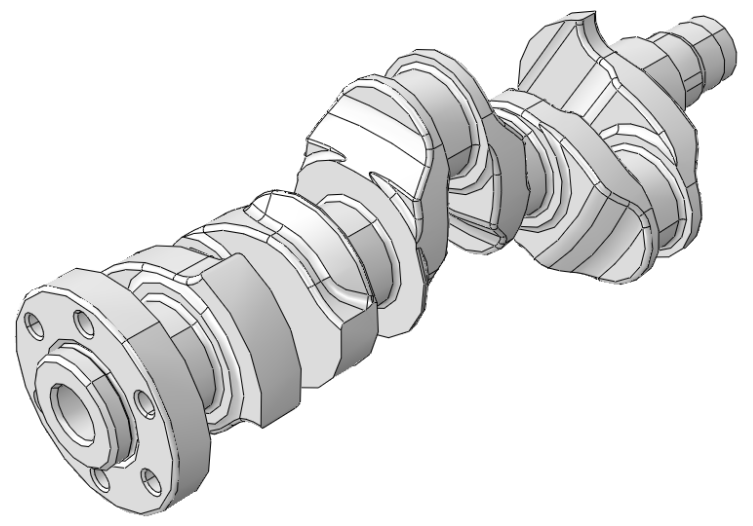

Fig. 1. Solid model generated in Catia v5 software.

\section{Simulation}

The first step in preparing the simulation was to determine a type of simulation. In order to calculate a form of the vibrations, a frequency simulation was selected and Lanczos solver was used. Because Abaqus software allows to determine the number of calculated vibration patterns or to determine the lower and upper limits of vibration frequencies, a frequency range between $10 \mathrm{~Hz}$ and $6000 \mathrm{~Hz}$ was set after initial calculations. The analysis of the crankshaft's own vibration was performed to determine its own frequency, so the model was not fixed in any place. Due to the complex geometry of the crankshaft model, Free Tet mesh grid was used for its discretisation. Material properties were defined by choosing the material as cast iron. The material properties adopted for the calculation are shown in the Table 1.

Table 1. Material properties (cast iron) of the analysed shaft.

\begin{tabular}{|c|c|}
\hline Name & Value \\
\hline Young Modulus & $178 \mathrm{GPa}$ \\
\hline Poisson Number & 0.33 \\
\hline Density & $7197 \mathrm{~kg} / \mathrm{m}^{3}$ \\
\hline
\end{tabular}

During simulation tests, mesh grid optimisation was performed by varying the size of a single element from an initial value of $9 \mathrm{~mm}$ to final size of $1.3 \mathrm{~mm}$. In the Figure 2 a ready-made model with mesh grids for cases 9 and $1.3 \mathrm{~mm}$ is presented. Numbers of elements for models are also included. Based on grids constructed in such a way, crankshaft frequencies were measured. The legends show the overall magnitude of the elements scaled in mm.

The Figure 3 shows a visualisation of all 10 modes of engine crankshaft vibration for the two extreme versions of the grid: 9 and $1.3 \mathrm{~mm}$. These are the first 10 free frequency modes between the assumed range. This range is assumed for the specific part - crankshaft from the opposed piston engine. The frequency value for every mode is calculated automatically by Abaqus software. The colours indicate the displacements. Because at given frequencies of the oscillation, the system falls into resonance, the displacements take the values corresponding to the destruction of the element. For a better visualisation and evaluation of the behaviour of the model, a uniform multiplication coefficient for all visualisations of 0.033 and the same legend of $0-1.35$ $\mathrm{mm}$ were adopted. The Table 2 below, shows results of the received vibration values for the two extreme cases of grid: 9 and $1.3 \mathrm{~mm}$.

Table 2. The crankshaft's own vibration frequencies for the $9 \mathrm{~mm}$ and $1.3 \mathrm{~mm}$ grid.

\begin{tabular}{|c|c|c|}
\hline $\begin{array}{c}\text { Mode } \\
\text { number }\end{array}$ & $\begin{array}{c}\text { Frequency [Hz] } \\
\text { for 9 } \mathbf{~ m m} \text { grid }\end{array}$ & $\begin{array}{c}\text { Frequency }[\mathbf{H z}] \\
\text { for } \mathbf{1 . 3} \mathbf{~ m m} \text { grid }\end{array}$ \\
\hline Mode 1 & 764.88 & 754.83 \\
\hline Mode 2 & 838.54 & 828.19 \\
\hline Mode 3 & 1445.7 & 1428.3 \\
\hline Mode 4 & 1715.1 & 1705.6 \\
\hline Mode 5 & 1950.1 & 1928.4 \\
\hline Mode 6 & 2563.7 & 2560.5 \\
\hline Mode 7 & 3300.2 & 3262.5 \\
\hline Mode 8 & 3872.2 & 3847.7 \\
\hline Mode 9 & 4731.1 & 4687.8 \\
\hline Mode 10 & 5179.7 & 5125.5 \\
\hline
\end{tabular}

$9 \mathrm{~mm} 27885$ elements



$1.3 \mathrm{~mm} 1888341$ elements

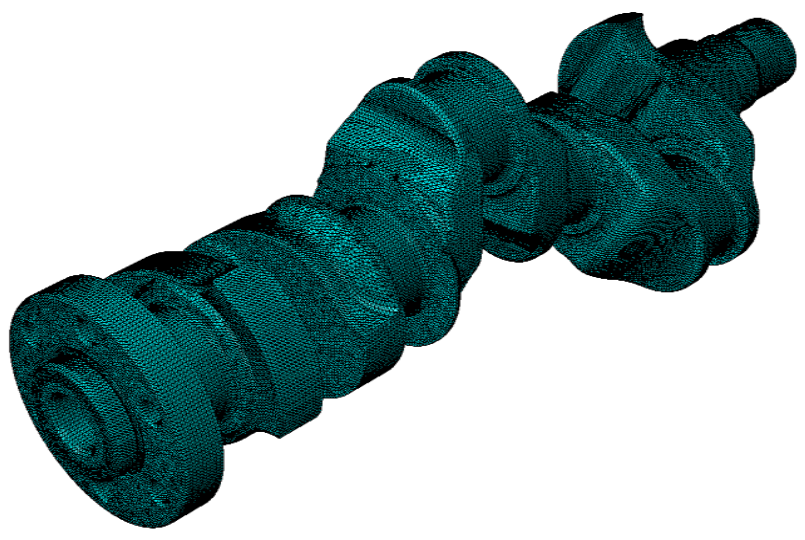

Fig. 2. Mesh grid of crankshaft. 


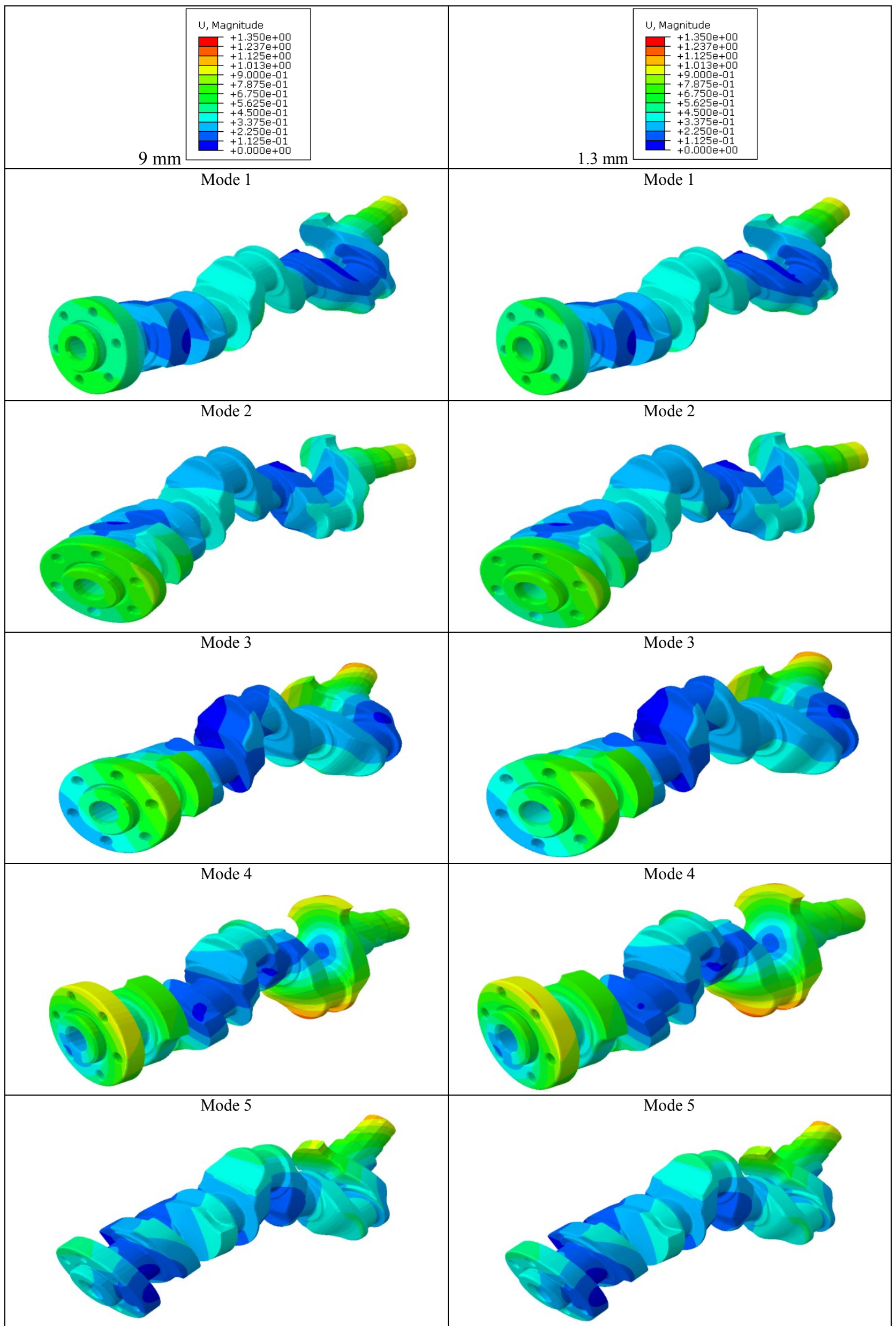






Fig. 3. Calculation results for $9 \mathrm{~mm}$ and $1.3 \mathrm{~mm}$ grids. 


\section{Results}

In addition, a range of changes in the frequencies value of received native vibration for each grid in the form of figures 4-8 were presented. Modes 1, 3, 5, 7 and 9 are referred to the left axis, modes 2, 4, 6, 8 and 10 are referred to right axis.

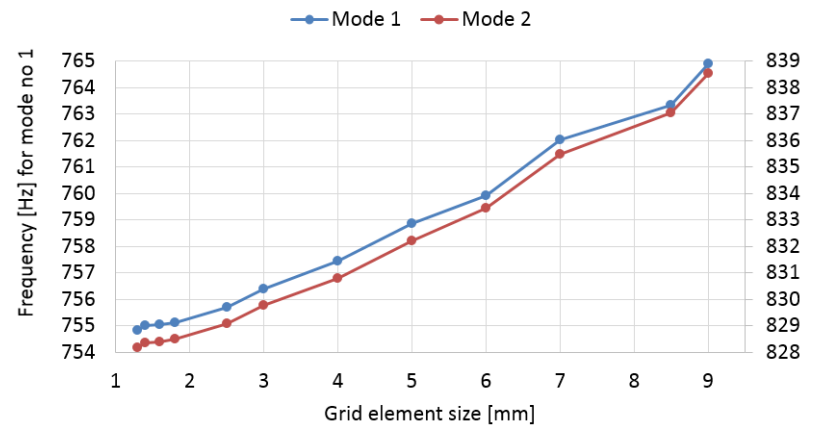

Fig. 4. Frequency values depending on grid size for the mode 1 and 2.

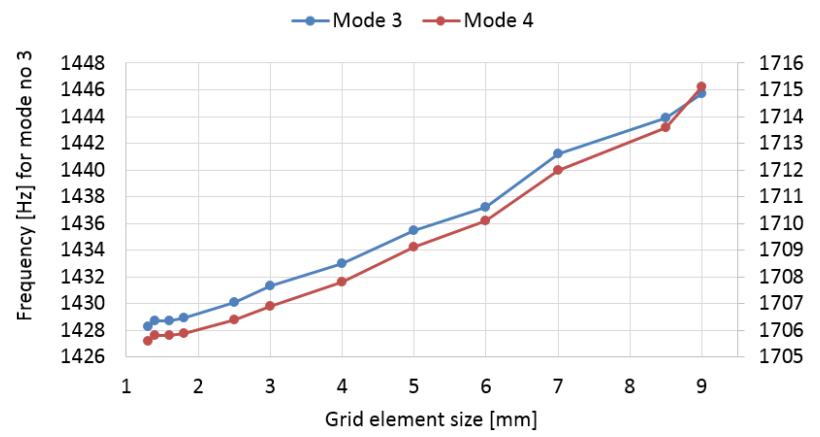

Fig. 5. Frequency values depending on grid size for the mode 3 and 4.

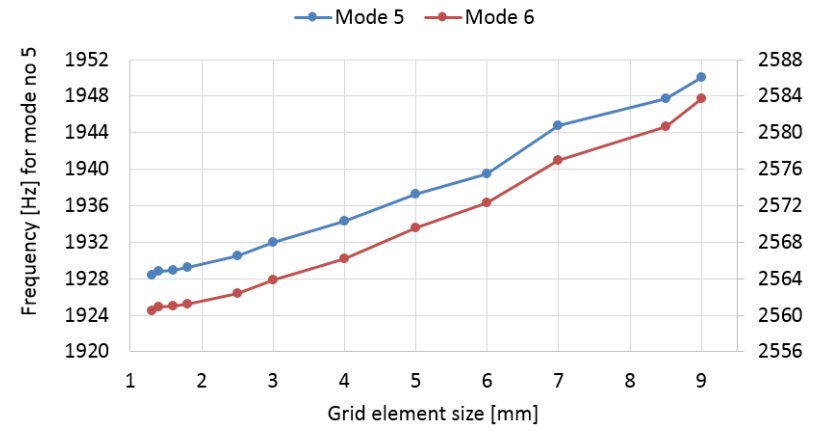

Fig. 6. Frequency values depending on grid size for the mode 5 and 6.

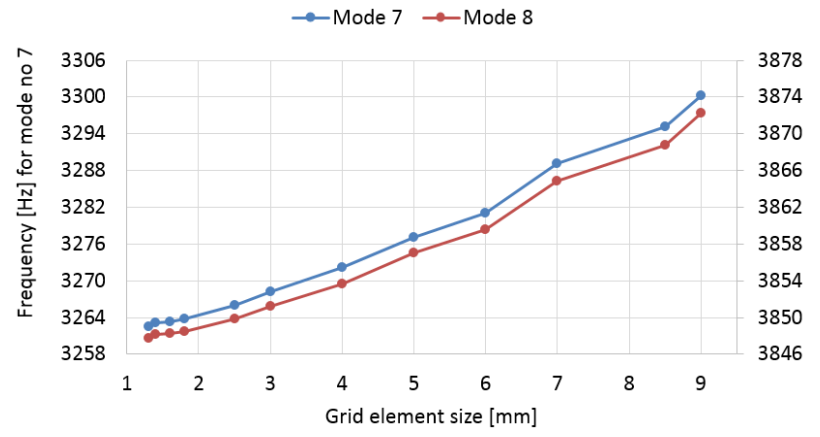

Fig. 7. Frequency values depending on grid size for the mode 7 and 8 .

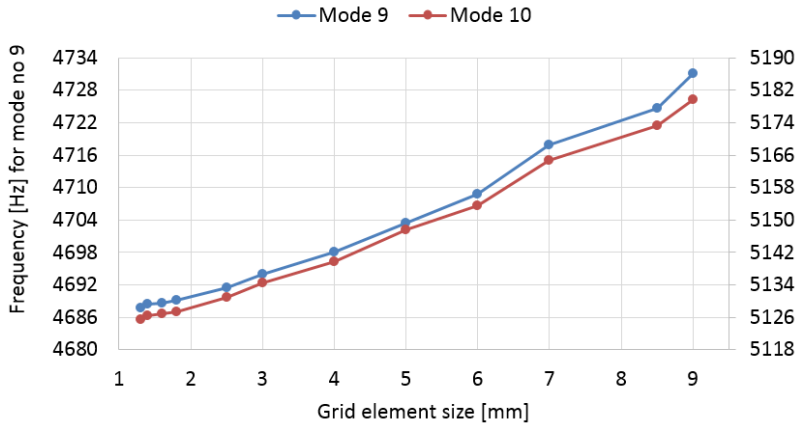

Fig. 8. Frequency values depending on grid size for the mode 9 and 10.

To check the mesh size quality for all cases, the dimensionless factor of $V_{i, j}$ was adopted, which is described by the equation:

$$
V_{i, j}=m_{\mathrm{i}, \mathrm{j}} / m_{\operatorname{mix} \mathrm{j}}
$$

Where:

$V$ - coefficient, $m_{\mathrm{i}, \mathrm{j}}-$ frequency value for $\mathrm{i}$-grid and $\mathrm{j}$-mode, $m_{\text {mix }}-$ minimum frequency value for $\mathrm{j}$-mode, $i$ - number of grid, $j$ - number of mode.

This factor was calculated for each of shaft vibration frequencies received, and is shown in the Figure 9.



Fig. 9. Characteristics of factor $V_{i, j}$ for all frequency modes.

The most likely to occur in reality are the first four forms of self-oscillation. They correspond visually to the figures below. As it is shown in the Figure 3, they have the same shape as presented below.

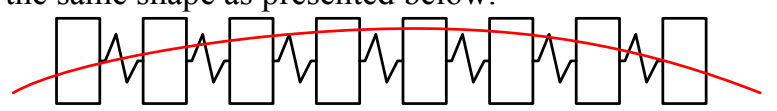

First and second mode

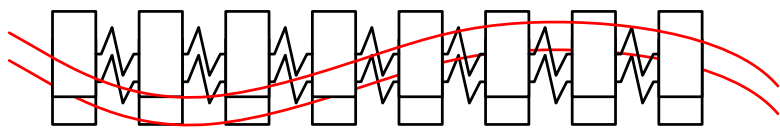

Third and fourth mode

Fig. 10. Schematic diagram of the first forms of vibration frequency modes. 


\section{Summary and conclusions}

As can be seen based on presented results of the simulation calculations in the Table 2 , the values of vibrations in the individual modes differ among themselves. These differences reach as much as $50 \mathrm{~Hz}$ for higher vibration values, but dimensionally they reach a maximum of approximately $1.3 \%$ (as shown in the Figure 9). According to the authors, these derogations are mainly due to the lack of reflection of the roundedness of the analysed solid in the case of worse quality of mesh grid. The grid of $9 \mathrm{~mm}$ (Figure 2) causes distortion of the crankshaft geometry, which affects other mass distributions in some parts of the crankshaft, consequently having an impact on results of the simulation. However, it should be noted that the visual representations of the form of the oscillation shown in the Figure 3, for both extreme grids look almost identical.

The grid with a single element size of $1.3 \mathrm{~mm}$ generates $1,888,341$ elements. Such a large number of elements results in a considerable prolongation of the simulation time. Further reduction in size of a single element is pointless: if the element is reduced to a size close to $0 \mathrm{~mm}$, results obtained (considering the downward trend of the curves in the Figures 4-8) would not significantly differ from results obtained for the 1.3 mm mesh.

In case of superficial calculation of the value of the oscillation, less accurate grid can be used. However, it should be noted that the selection of grid elements and its compaction must be in line with the geometric model. Nevertheless, to obtain very precise calculations, the grid should be compacted as accurately as possible. It should be considered in the future in case of calculating new engine parts.

This allows the authors to say that if vibrations are calculated for visualisation purposes only, a mesh with a bigger size of elements can be applied.
Acknowledgement: This work has been realised in the cooperation with The Construction Office of WSK "PZL-KALISZ" S.A." and is a part of Grant Agreement No. POIR.01.02.00-00-0002/15 financed by the Polish National Centre for Research and Development.

\section{References}

1. W. Mitianiec, K. Buczek, Technical Journal, Cracow University of Technology Publish House, $\mathbf{z}$. 8-M/2008 (2008).

2. A. S. Mendes, Proceedings of the Institution of Mechanical Engineers Part K Journal of Multi-body Dynamics 222, 2 (2008).

3. W. Homik, Pol Marit Res, no 3, 43-47, (2011).

4. S.S. Mohtasebi, H. Afshari, H. Mobli, J of Appl Scien, 6, 3 (2006).

5. T. Łodygowski, Kąkol W., Finite element method in selected problems of mechanics engineering structures (in polish), Poznań University of Technology Publish House, (1994).

6. R. Neugebauer, C. Scheffler, M. Wabner, CIRP Journal of Manufacturing Science and Technology 4 (2011).

7. A. Zielińska, P. Wyciślok, High-speed Tracked Vehicles (in polish), 18, 2 (2003).

8. P. Magryta, M. Biały, K. Siadkowska, Logistyka 3 (2015).

9. T. Markowski, G. Budzik, J. Pacana, Engineering Modeling (in polish) 39 (2010).

10. Ramesha C. M., Abhijith K. G., Abhinav S., Abhishek R., Chetan S. N., IJETAE 5, 6 (2015).

11. Deshbhratar R. J., Suple Y. R., IJMER, 2, 5 (2012).

12. Horváth P., Égert J., Dynamic, Acta Technica Jaurinensis 8, 4 (2015). 